\title{
Profil Pasien Operasi Vitreoretinal di Instalasi Bedah Sentral RSUP Prof. Dr. R. D. Kandou Manado Periode Juli 2018 - Juli 2019
}

\author{
${ }^{1}$ Githa P. Boedihardjo \\ ${ }^{2}$ Vera Sumual \\ ${ }^{2}$ Imelda Najoan
}

\author{
${ }^{1}$ Program Studi Pendidikan Dokter Fakultas Kedokteran Universitas Sam Ratulangi Manado \\ ${ }^{2}$ Bagian Ilmu Kesehatan Mata Fakultas Kedokteran Universitas Sam Ratulangi Manado \\ Email: githaboe@gmail.com
}

\begin{abstract}
Retinal disorders are ranked as the fourth most common eye disease in Indonesia. Retinal and vitreous disorders can cause severe visual impairment and even blindness. This study was aimed to determine the profile of patients undergoing vitrectomy at the Central Surgical Installation of Prof. Dr. R. D. Kandou Hospital Manado form July 2018 - July 2019. This was a retrospective and descriptive study using medical record data of vitreoretinal surgery patients. The results showed that there were 31 patients who underwent vitreoretinal surgery, consisting of 16 males (51.6\%) and 15 females (48.4\%). Based on the type of surgery; vitrectomy was performed on 15 patients $(48.4 \%)$; vitrectomy + laser photocoagulation on 7 patients (22.7\%); vitrectomy + injection of gas dan silicon oil on 3 patients $(9.7 \%)$; and 2 patients each (6.4\%) for gas and silicon oil injection, laser photocoagulation, and vitrectomy + gas injection and silicon oil + laser photocoagulation. In conclusion, the most common type of surgery was vitrectomy based on retinal detachment. Most patients were retired and at the age of 46-65 years.
\end{abstract}

Keywords: vitreoretinal surgery, vitreoretinal abnormalities, vitrectomy, retinal detachment

\begin{abstract}
Abstrak: Gangguan retina berada di urutan ke empat sebagai penyakit mata terbanyak di Indonesia. Bila terjadi gangguan pada retina dan vitreous bisa menimbulkan gangguan penglihatan yang berat bahkan kebutaan. Penelitian ini bertujuan untuk mengetahui profil pasien yang menjalani operasi vitreoretinal di Instalasi Bedah Sentral RSUP. Prof. Dr. R. D. Kandou Manado periode Juli 2018 - Juli 2019. Jenis penelitian ialah deskriptif retrospektif dengan menggunakan data rekam medik pasien operasi vitreo retina. Hasil penelitian mendapatkan 31 pasien yang menjalani operasi vitreoretinal, dengan jenis kelamin laki-laki sebanyak 16 pasien $(51,6 \%)$ dan perempuan 15 pasien $(48,4 \%)$. Berdasarkan jenis operasi diperoleh data vitrektomi pada 15 pasien $(48,4 \%)$, vitrektomi + laser fotokoagulasi 7 pasien $(22,7 \%)$, vitrektomi + injeksi gas dan silicon oil 3 pasien $(9,7 \%)$, dan masing-masing 2 pasien $(6,4 \%)$ untuk jenis operasi injeksi gas + silicon oil, jenis operasi laser fotokoagulasi, dan vitrektomi + injeksi gas dan silicon oil + laser fotokoagulasi. Simpulan penelitian ini ialah jenis operasi yang terbanyak dilakukan yaitu vitrektomi, dengan indikasi ablasio retina. Sebagian besar pasien berada pada kategori usia 46-65 tahun, dengan pekerjaan pensiunan.
\end{abstract}

Kata kunci: operasi vitreo retina, kelainan vitreo retina, vitrektomi, ablasio retina

Mata merupakan indera penglihatan. Mata manusia dapat dijelaskan seperti fungsi alat kamera, dimana cahaya masuk atau sinar jatuh pada retina yang kemudian cahaya dibiaskan oleh sebuah lensa. ${ }^{1}$
Gangguan penglihatan masih menjadi masalah kesehatan di Indonesia, dengan peningkatan setiap tahunnya. Survei kesehatan indera menunjukkan $1,5 \%$ penduduk Indonesia mengalami kebutaan yang dise- 
babkan oleh katarak (52\%), glaukoma $(13,4 \%)$, kelainan refraksi $(9,5 \%)$, gangguan retina $(8,5 \%)$, kelainan kornea $(8,4 \%)$, dan penyakit mata lainnya. ${ }^{2}$ Berdasarkan data tersebut, gangguan retina berada di urutan ke empat sebagai penyakit mata terbanyak di Indonesia.

Retina adalah lapisan tipis yang terletak pada bagian belakang mata yang berfungsi mengubah cahaya menjadi sinyal saraf sedangkan vitreous merupakan suatu gel transparan dan tidak berwarna, yang mengisi ruang diantara lensa mata dan retina. Gangguan pada retina dan vitreous bisa menimbulkan gangguan penglihatan yang berat bahkan kebutaan. ${ }^{3}$

Berdasarkan Standar Kompetensi Dokter Indonesia 2012, gangguan vitreo retina terdiri atas dua bagian yaitu gangguan vitreous dan gangguan retina. Gangguan vitreous yaitu perdarahan vitreous, sedangkan untuk gangguan retina terdiri atas beberapa penyakit yaitu; ablasio retina, perdarahan retina, degenerasi makula karena usia, retinopati, dan korioretinitis.

\section{METODE PENELITIAN}

Penelitian ini dilakukan di Bagian Rekam Medik RSUP Prof. Dr. R. D. Kandou Manado. Jenis penelitian ini ialah deskriptif retrospektif dengan menggunakan data rekam medik pasien operasi vitreo retina Subjek penelitian ialah semua pasien yang menjalani operasi vitreoretinal di Instalasi Bedah Sentral RSUP Prof. Dr. R. D. Kandou Manado periode Juli 2018 - Juli 2019. Variabel penelitian yaitu berdasarkan jenis operasi, jenis gangguan, jenis kelamin, usia, dan pekerjaan.

\section{HASIL PENELITIAN}

Gambar 1 memperlihatkan sebanyak 31 pasien yang menjalani operasi vitreoretinal di Instalasi Bedah Sentral RSUP Prof. Dr. R. D. Kandou Manado periode Juli 2018 - Juli 2019. Jenis operasi yang terbanyak ialah vitrektomi yaitu sebanyak 15 pasien $(48,4 \%)$ dari 31 pasien, diikuti oleh jenis operasi kombinasi vitrektomi + laser fotokoagulasi yaitu sebanyak tujuh pasien $(22,7 \%)$.

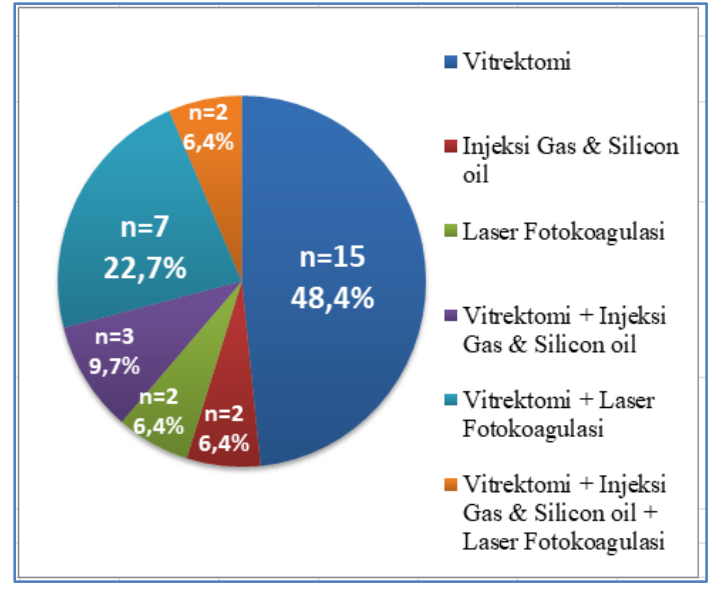

Gambar 1. Distribusi pasien yang menjalani operasi vitreoretinal berdasarkan jenis operasi

Gambar 2 memperlihatkan distribusi pasien operasi vitreoretinal berdasarkan jenis gangguan; yang terbanyak ialah pasien yang terdiagnosis ablasio retina (retinal detachment) (41,9\%), diikuti oleh perdarahan vitreous $(22,6 \%)$.

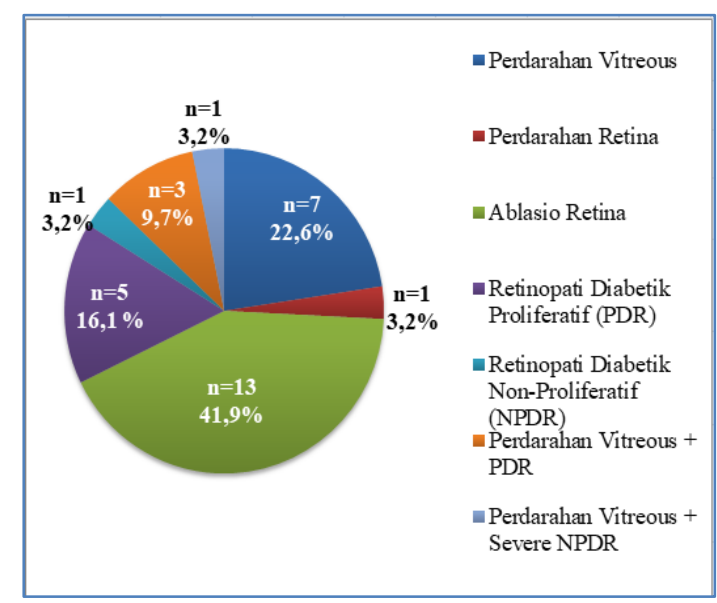

Gambar 2. Distribusi pasien yang menjalani operasi vitreoretinal berdasarkan jenis gangguan

Gambar 3 memperlihatkan bahwa berdasarkan jenis kelamin, pasien yang menjalani operasi vitreoretinal pada jenis kelamin laki-laki dan perempuan hampir sama banyak, hanya selisih satu pasien.

Gambar 4 memperlihatkan bahwa berdasarkan usia, kelompok usia 46-65 tahun merupakan yang paling banyak yaitu sebanyak 20 pasien $(64,5 \%)$ dari 31 pasien, diikuti oleh kelompok usia >66 tahun $(19,4 \%)$, dan yang paling sedikit pada kategori usia $<25$ tahun $(6,5 \%)$. 


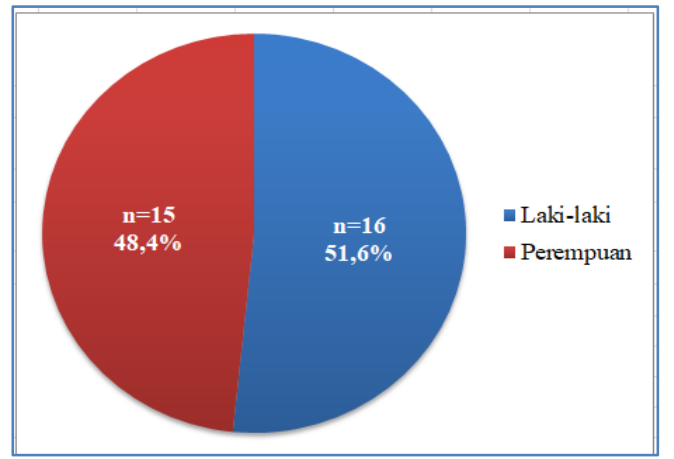

Gambar 3. Distribusi pasien yang menjalani operasi vitreoretinal berdasarkan jenis kelamin

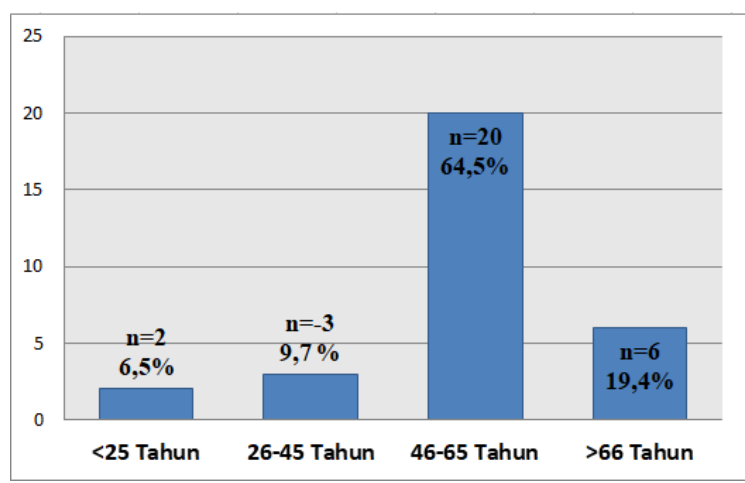

Gambar 4. Distribusi pasien yang menjalani operasi vitreoretinal berdasarkan usia

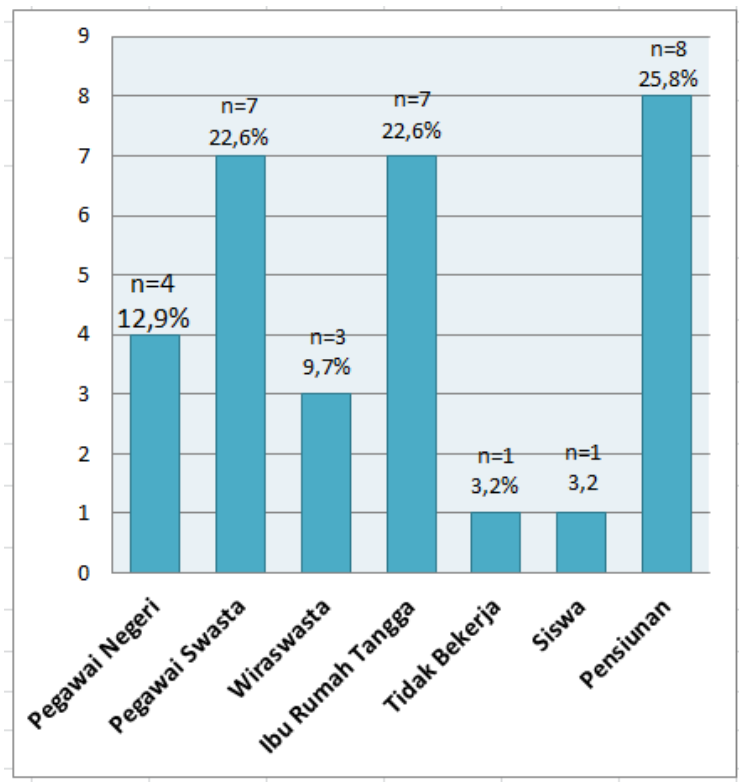

Gambar 5. Distribusi pasien yang menjalani operasi vitreoretinal berdasarkan pekerjaan

Gambar 5 memperlihatkan distribusi pasien operasi vitreoretinal berdasarkan pekerjaan. Yang terbanyak ialah pensiunan $(25,8 \%)$, diikuti oleh pekerjaan pegawai swasta dan ibu rumah tangga (masing- masing 22,6\%), dan pekerjaan yang paling sedikit yaitu siswa dan pasien yang tidak bekerja (masing-masing 3,2\%).

\section{BAHASAN}

Pada penelitian ini didapatkan sebanyak 31 pasien yang menjalani operasi vitreoretinal di Instalasi Bedah Sentral RSUP Prof. Dr. R. D. Kandou Manado periode Juli 2018 - Juli 2019. Distribusi pasien operasi vitreoretinal berdasarkan jenis operasi menunjukkan vitrektomi yang terbanyak dilakukan pada pasien dengan gangguan vitreoretinal $(48,4 \%)$, diikuti oleh kombinasi vitrektomi + laser fotokoagulasi $(22,7 \%)$. Hal ini sesuai dengan penelitian Syah A et $\mathrm{al}^{4}$ di Rumah Sakit Mata Cicendo Bandung pada tahun 2006, yang menyatakan bahwa operasi jenis vitrektomi paling banyak dilakukan yaitu 77 dari 129 pasien yang menjalani operasi vitreoretinal.

Distribusi pasien operasi vitreoretinal berdasarkan jenis gangguan memperlihatkan pasien yang terdiagnosis ablasio retina (retinal detachment) yang terbanyak dilakukan operasi vitreoretinal $(41,9 \%)$, diikuti perdarahan vitreous $(22,6 \%)$. Hal ini sejalan dengan laporan oleh United Kingdom National Ophthalmology ${ }^{5}$ tentang data campuran kasus bedah vitreoretinal di Inggris tahun 2013 yang menyatakan bahwa indikasi paling umum untuk dilakukan operasi vitreoretinal yaitu ablasio retina (retinal detachment) sebanyak 48,5\% dari 8741 pasien. Penelitian yang dilakukan di Rumah Sakit Mata Provinsi Sulawesi Utara pada tahun 2016 oleh Sinaga et al $^{6}$ juga menunjukkan ablasio retina (retinal detachment) merupakan indikasi paling sering dilakukan operasi vitrektomi.

Berdasarkan jenis kelamin, pasien yang menjalani operasi vitreoretinal hampir sama banyak untuk kedua jenis kelamin. antara jenis kelamin. Data tersebut selaras dengan laporan oleh United Kingdom National Ophthalmology $y^{5}$ tentang data campuran kasus operasi vitreoretinal di Inggris pada tahun 2013, dari 8741 pasien didapatkan pasien dengan jenis kelamin laki-laki yaitu sebanyak 4539 pasien 
$(51,9 \%)$ sedangkan pasien berjenis kelamin perempuan sebanyak 4190 pasien $(47,9 \%)$; terdapat pasien yang tidak teridentifikasi jenis kelaminnya karena data rekam medik tidak lengkap yaitu sebanyak 12 pasien $(0,2 \%)$. Tidak terdapatnya perbedaan antara kedua jenis kelamin mungkin disebabkan karena meningkatnya kesadaran akan pentingnya kesehatan. ${ }^{5}$

Berdasarkan usia, kelompok usia 46-65 tahun merupakan yang terbanyak $(64,5 \%)$ diikuti kelompok usia $>66$ tahun $(19,4 \%)$, dan yang paling sedikit kategori usia $<25$ tahun $(6,5 \%)$. Data tersebut seusai dengan laporan oleh United Kingdom National Ophthalmology ${ }^{5}$ tentang data campuran kasus operasi vitreoretinal di Inggris pada tahun 2013 bahwa usia pasien yang menjalani operasi vitreoretinal yang pertama berada pada rentang usia 61-70 tahun.

Distribusi pasien operasi vitreoretinal berdasarkan pekerjaan memperlihatkan pasien dengan pekerjaan pensiunan merupakan yang paling banyak $(25,8 \%)$ dari 31 pasien, diikuti oleh pekerjaan pegawai swasta dan ibu rumah tangga $(22,6 \%)$, dan pekerjaan yang paling sedikit yaitu siswa dan pasien yang tidak bekerja $(3,2 \%)$. Hal ini mungkin berhubungan dengan usia pasien yang menjalani operasi vitreoretinal yaitu terbanyak pada kategori dewasa sampai lanjut usia. Kategori usia tersebut sudah termasuk dalam pekerjaan yang disebutkan.

\section{SIMPULAN}

Berdasrkan hasil penelitian ini dapat disimpulkan bahwa pada pasien operasi vitreoretinal di Instalasi Bedah Sentral RSUP. Prof. Dr. R. D. Kandou Manado periode bulan Juli 2018 - Juli 2019 yang paling banyak didapatkan ialah jenis operasi vitrektomi atas indikasi ablasio retina (retinal detachment), serta usia 46-65 tahun dengan pekerjaan pensiunan. Tidak terdapat perbedaan berarti antara kedua jenis kelamin laki-laki dan perempuan.

Bagi pemerintah dan petugas medis disarankan bekerja sama melakukan upaya promotif dan preventif pada masyarakat terhadap kelainan mata khususnya kelainan vitreo retina, agar dapat mengendalikan penyakit sehingga tidak perlu dilakukan tindakan kuratif atau khususnya operasi vitreoretinal. Masyarakat diharapkan dapat meningkatkan kepedulian tentang pentingnya kesehatan khususnya kesehatan mata dengan melakukan pemeriksaan awal/ skrining dan pemeriksaan berkala, agar dapat mencegah terjadinya suatu penyakit. Bagi pasien yang sudah menjalani operasi vitreoretinal sebaiknya melakukan kontrol secara rutin untuk melihat perkembangan perbaikan dari suatu penyakit. Bagi penelitian lebih lanjut disarankan untuk mencari faktor-faktor risiko kelainan vitreoretinal.

\section{DAFTAR PUSTAKA}

1. Irianto K. Anatomi dan Fisiologi. Bandung; Alfabeta, 2013; p. 388.

2. Gangguan penglihatan masih menjadi masalah kesehatan. Kementerian Kesehatan Republik Indonesia, 2010 [cited 2019 Aug27]. Available from: http://www. depkes.go.id/article/print/845/gangguan -penglihatan-masih-menjadi-masalahkesehatan.html

3. Pelayanan retina. RSUPN. Dr. Cipto Mangunkusumo; 2017 [cited 2019 Aug13]. Available from: https://www. rscm.co.id/index.php?XP_webviewruju kan_menu=0\&pageid $=16 \&$ title=Pelaya nan\%20Retina

4. Syah A, Sovani I, Panggabean D. The application of silicone oil as an intraocular tamponade in vitreoretinal surgery at Cicendo Eye Hospital. Buletin Seminat Retina; 2006;11(1):12-5.

5. Jackson TL, Donachie PHJ, Sparrow JM, Johnston RL. United Kingdom National Ophthalmology Database Study of Vitreoretinal Surgery: report 1; case mix, complications, and cataract. Eye (London, England). The Scientific Journal of The Royal College of Ophthalmologist. US National Library of Medicine National Institutes of Health; 2013 [cited 2019 Nov 9]. Available from: https://www.ncbi.nlm. nih.gov/pmc/articles/PMC3650265/

6. Sinaga RT, Rares L, Sumual V. Indikasi vitrektomi pada kelainan retina di Balai Kesehatan Mata Masyarakat (BKMM) Provinsi Sulawesi Utara periode Januari-Desember 2014. e-CliniC. 2016;4(1):359-62. 